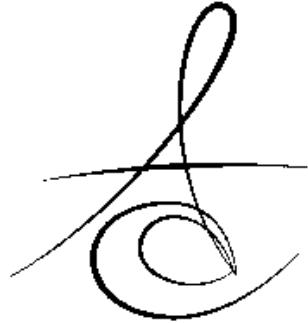

Makale Kodu/Article code: 2804

Makale Gönderilme tarihi: 21.04.2016

Kabul Tarihi: 27.07 .2016

\section{FARKLI POST-KOR SİSTEMLERİNİN KIRILMA DAYANIMININ İN-VİTRO OLARAK DEĞERLENDİRİLMESİ ${ }^{*}$}

\section{IN-VITRO EVALUATION OF FRACTURE RESISTANCE OF DIFFERENT POST-CORE SYSTEMS *}

\author{
Yrd. Doç. Dr. Orhun EKREN *
}

\section{Öz}

Amaç: Bu çalışmanın amacı döküm $\mathrm{Ni}-\mathrm{Cr}$, fiber post ve kompozit kor ve preslenmiş lithiumdisilicate post-kor sistemlerinin kırılma dirençlerinin karşılaştırmalı değerlendirilmesidir.

Gereç ve Yöntem: Toplanan maksiler anterior dişlere kanal tedavisi uygulandı. Kök uzunlukları $10 \mathrm{~mm}$ olacak şekilde standardize edildikten sonra kök kanallarına post yuvaları hazırlandı. Toplamda 30 adet diş tesadüfi olarak 3 gruba ayrıldı(n=10). Post yuvalarının ölçüsü patern rezin ile alındı ve laboratuara gönderildi. Laboratuar işlemleri sonrası $\mathrm{Ni}-\mathrm{Cr}$ ve Li-disilikat örnekler hazırlandı. Hazırlanan post korlar ve fiber postlar duel-kür rezin siman ile post yuvalarına simante edildi. Test örnekleri oda Isısında 24 saat bekletildikten sonra $7{ }^{\circ} \mathrm{C}$ - $50^{\circ} \mathrm{C}$ arasında termal döngüye maruz bırakıldı. Termal döngü sonrası test örneklerine testometrik cihazında $1 \mathrm{~mm} / \mathrm{dk}$ hızla örnek kırılana kadar kuvvet uygulandı. SPSS programı kullanılarak Tek yönlü ANOVA ve Dunnett T3 testi $(a=0.05)$ ile verilerin istatistiği yapıldı.

Bulgular: Hazırlanan döküm $\mathrm{Ni}-\mathrm{Cr}$ test örneklerinin kırılma direnci $334.2 \pm 130.5 \mathrm{~N}$, fiber-post kompozit kor örneklerin kırılma direnci $280.2 \pm 62.5 \mathrm{~N}$, li-disilikat örneklerin kırılma direnci ise $162.8 \pm 28.6 \mathrm{~N}$ bulunmuştur. $\mathrm{Ni}-\mathrm{Cr}$ döküm alaşımı kullanılan test örnekleri en yüksek kırılma direncini gösterirken, lidisilikat grubundaki örnekler en düşük kırılma direncini göstermiştir. $\mathrm{Ni}-\mathrm{Cr}$ ve fiber post kompozit kor test örnekleri arasında istatistiki olarak anlamlı fark bulunamamıştır

Sonuç: Çalışmanın sınırları dahilinde, estetik avantajları yüksek olmasına rağmen post kor yapımında Li-disilikat kullanılması kırılma direncinin göreceli düşük olması nedeniyle risk taşımaktadır.

Anahtar kelimeler: Post-kor, kırılma direnci, aşırı hasarlı dişler

\section{ABSTRACT}

Aim: The aim of this study was to evaluate and compare the fracture resistance of post-core systems made of cast $\mathrm{Ni}-\mathrm{Cr}$, fiber post and composite core and pressed li-disilicate post-core systems.

Material and Methods: Root canal treatment was conducted on collected sound maxillary anterior teeth. After standardization of root length as $10 \mathrm{~mm}$, post space was prepared. A total of 30 teeth were divided into 3 groups $(\mathrm{n}=10)$ randomly for $\mathrm{Ni}-\mathrm{Cr}$, lithiumdisilicate and fiber post-composite core. The impression of post space was taken with pattern resin. Following the laboratory procedures, $\mathrm{Ni}-\mathrm{Cr}$ and lithiumdisilicate post-core were prepared. Fabricated post-cores and fiber posts were luted with duel-cure resin cement. After 24 hours test specimens were subjected to thermal cycling between $7{ }^{\circ} \mathrm{C}$ and $50{ }^{\circ} \mathrm{C}$ and were subjected to fracture test with a cross-head speed of $1 \mathrm{~mm} / \mathrm{min}$. Data were subjected to one-way ANOVA followed by Dunnett T3 tests for statistical analyses $(a=0.05)$ using SPSS 21.

Results: The mean and standard deviation of maximum fracture force was $334.2 \pm 130.5 \mathrm{~N}$ for Cast $\mathrm{Ni}-\mathrm{Cr}, 280.2 \pm 62.5 \mathrm{~N}$ for Fiber post and $162.8 \pm 28.6$ $\mathrm{N}$ for Lithium-disilicate. Teeth which received $\mathrm{Ni}-\mathrm{Cr}$ post cores had highest fracture resistance however lithiumdisilicate group had the least. There was no statistically significant difference between cast $\mathrm{Ni}-\mathrm{Cr}$ and fiber post groups.

Conclussions: Within the limitations of this study it can be concluded that despite aesthetic advantages lithiumdisilicate ceramics are not an ideal material for post-core fabrication due to its low fracture resistance. Key Words: Post-cores, fracture resistance, Excessively damaged teeth

${ }^{*}$ Çukurova Üniversitesi, Diş Hekimliği Fakültesi, Protetik Diş Tedavisi AD.

* Bu çalışma C.Ü Bilimsel Araştırma Projeleri koordinasyon birimi tarafindan DHF2012BAP1 numaralı proje kodu ile desteklenmiştir. 


\section{GİRIŞ}

İleri derecede kron harabiyeti olan dişler postkor sistemlerle kök kanallarından destek alınarak restore edilir ${ }^{1}$. Post-kor materyali olarak diş hekimliği pratiğinde döküm metal alaşımları (Ni-Cr alaşımları), fiberler, prefabrike Zirkonyum alaşımları gibi çeşitli malzemeler kullanılmaktadır². Döküm alaşımlar, özellikle üst çene ön bölge dişlerin restorasyonlarında estetik dezavantajlarından dolayı tercih edilmemektedir ${ }^{3,4}$.

Fiber post sistemleri diş dokusu ile uyumlu mekanik özellikleri, estetik avantajları ve kullanım kolaylığı açısından sık tercih edilmektedir. Ancak özellikle karbon fiber postlar yüzeylerindeki düşük hidroxil iyonları nedeniyle diş dokusuna ve kor malzemesi olarak kullanılacak kompozite iyi bağlanamamakta ve bu zayıf bağlantı restorasyonda başarısızlığa neden olmaktadır ${ }^{5}$.

Lityumdisilikat(IPS Press e-max) ile güçlendiriImiş cam seramik restorasyonlar yüksek estetik özelliklerinden dolayı üst çene ön bölge dişlerinin lamine veneer veya tam seramik veneer ile restorasyonunda sıklıkla tercih edilmektedir. Lityumdisilikat ile güçlendirilmiş seramikler diş dokusuna benzer optik özellikler taşımaktadır ve çok farklı renk seçenekleri mevcuttur ${ }^{6-}$ ${ }^{9}$. Ayrıca içeriğindeki yüksek silisyum silanlanmasını ve diş dokusu ile bağlantısını güçlendirmektedir. Literatürde lityumdisilikat seramiklerin postkor sistemlerde kullanılmasıyla ilgili herhangi bir çalışma mevcut değildir.

Bu projenin amacı döküm metal(Ni-Cr)postkor, fiber postkor ve IPS Empress tek parça post kor sistemlerin diş dokusu ile bağlantısını ve kırılma dayanımını karşılaştırmalı olarak test etmektir.

\section{Gereç ve Yöntem:}

Çalışmada post kor sistemlerinin test edilmesi için yeni çekilmiş üst çene santral ve kanin dişleri toplandı. Bahsi geçen çekilmiş dişler \%5 lik $\mathrm{NaOCl}$ solüsyonunda dezenfekte edildikten sonra yıkanıp kanal tedavileri yapıldı. Kanal şekillendirmesi \%5 lik sodyum hipoklorid ve serum fizyolojik irrigasyonu yardımı ile 40 no kanal eğesi final eğe olacak şekilde genişletildi. Lateral kondansayon ile gütaperka (President Dental, Deisburg, Almanya) yardımı ile kanallar dolduruldu. Kanal patı olarak AH26 (De Trey AG Co, İsviçre) kullanıldı. Kanal tedavisi sonrası dişler 24 saat açık havada bekletildi. Dişlerin kök uzunlukları $10 \mathrm{~mm}$ olacak şekilde kron kısımlarından kesildi. Kök ucunda $3 \mathrm{~mm}$ gütaperka kalacak şekilde kronal kısımdaki gütaperka uzaklaştırıldı. Kanal yuvaları post yuvası hazırlama frezleri (Cytec Blanco,E Hahnenkart $\mathrm{GmbH}$, Konigs- bach-Stein, Almanya) ile 4 numaraya kadar frez sırası gözetilerek genişletildi. Fiber post uygulanacak dişler haricinde, hazırlanan post yuvalarının ölçüsü akrilik resinle alındı(Pattern resin, GC Corp, Tokyo, Japan). Kor kısmının standardizasyonu için silikon indeks kullanıldı. Hazırlanan akrilik modeller örnek hazırlanması için laboratuara gönderildi. İlgili laboratuarda $\mathrm{Ni}-\mathrm{Cr}$ alaşımı(Wiron 99, Bego, Bremen, Germany) ve Li-disilikat (IPS e.max Press, Ivoclar Vivadent, IvoclarVivadent, Schaan, Liechtenstein) post kor test örnekleri hazırlandı $(n=10)$. Hazırlanan örnekler şekillendirilen kök kanalları içerisine dual-cure resin siman ile (Panavia F 2.0, Kuraray Medical; Tokyo, Japan) simante edildi. Fiber $\operatorname{post}(n=10)$ grubunda ise fiber postlar dual-cure resin siman ile simante edildikten sonra diğer gruplarda kor şekillendirilmesinde kulanılan silikon indeks yardımı ile kompozit (Clearfi Majesty, Kuraray Medical; Tokyo,Japan) kullanılarak kor kısmı oluşturuldu. Hazırlanan test örnekleri oda ısısında 24 saat bekletildikten sonra $7{ }^{\circ} \mathrm{C}-50^{\circ} \mathrm{C}$ arasında $5000 \mathrm{kez}$ termal döngüye maruz bırakıldı. (Şekil1) Termal döngü sonrası dişler kole seviyesinden $2 \mathrm{~mm}$ uzakta olacak şekilde paslanmaz çelik silindir kalıplara yerleştirildi. (Şekil2) Kırılma testi örneklerine universal test cihazında (Testometric M500 25 kN, Testometric Co., Rochdale, UK) 1mm/dk hızla örnek kırılana kadar örneklerin insizal kısımlarından kuvvet uygulandı.(Şekil 3) Test sonunda SPSS programı kullanılarak Tek yönlü ANOVA ve Dunnett T3 testi $(a=0.05)$ ile verilerin istatistiği yapıldı.

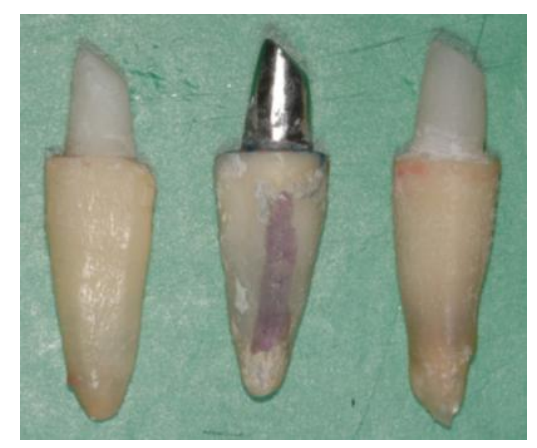

Şekil 1. Simantasyonu yapılmış post-korlar 


\section{TARTIŞMA}
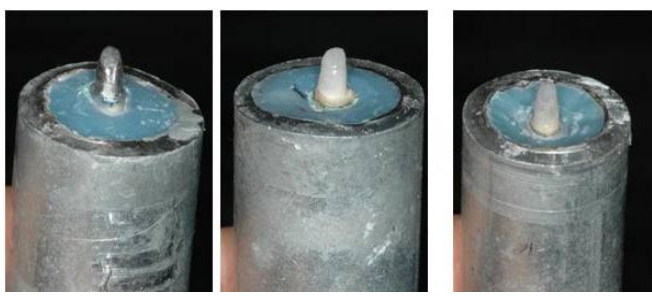

Şekil 2. Paslanmaz çelik kalıplara yerleştirilmiş test örnekleri

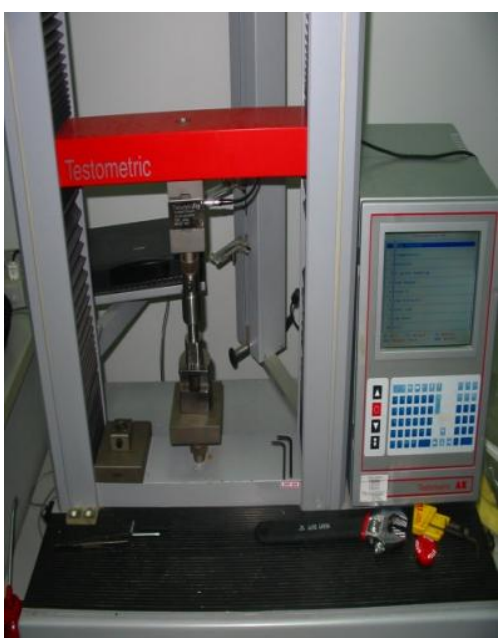

Şekil 3. Testometrik test cihazı

\section{BULGULAR}

Test örneklerinin ortalama kırılma dirençleri ve standart sapmaları Tablo 1 de verilmektedir. Döküm $\mathrm{Ni}-\mathrm{Cr}$ test örneklerinin kırılma direnci $334.2 \pm 130.5 \mathrm{~N}$, fiber-post kompozit kor örneklerin kırılma direnci 280.2 $\pm 62.5 \mathrm{~N}$, Li-disilikat örneklerin kırılma direnci ise 162.8 $\pm 28.6 \mathrm{~N}$ bulunmuştur. $\mathrm{Ni}-\mathrm{Cr}$ döküm alaşımı kullanılan test örnekleri en yüksek kırılma direncini gösterirken, Li-disilikat grubundaki örnekler en düşük kırılma direncini göstermiştir. Ni-Cr ve fiber post kompozit kor test örnekleri arasında istatistiki olarak anlamlı fark bulunmamıştır.

Tablo1. Çalışmada elde edilen ortalama kırılma kuvvetleri ve standart sapma

\begin{tabular}{|l|l|l|}
\hline Gruplar & $\mathrm{N}$ & Ort Kuvvet \pm Std.Dev (N) \\
\hline Döküm Ni-Cr & 10 & $334.2 \pm 130.5 \mathbf{a}^{*}$ \\
\hline Fiber post & 10 & $280.2 \pm 62.5 \quad$ a \\
\hline Lithiumdisilicate & 10 & $162.8 \pm 28.6 \quad$ b \\
\hline
\end{tabular}

*Farklı harfler istatistiksel anlamlı farkı belirtmektedir
Günümüzde estetik ihtiyaçların artması ve adeziv teknolojisindeki son gelişmeler, hekimleri ön ve arka dişlerdeki madde kayıplarını gidermek ve aynı zamanda estetiği sağlamak için seramik full kron, laminate vener, inley ve onley restorasyonları uygulamaya yönlendirmiştir ${ }^{10-14}$. Bu tür indirekt restorasyonların simantasyonu sırasında seçilecek olan yapıştırma simanının mekanik özelliklerinin iyi olması restorasyonun ömrünü uzatırken, renginin diş rengine ve restorasyon rengine yakın olması restorasyon altından farklı renk yansımalarını önleyerek estetiği olumlu yönde geliştirecektir. Mekanik ve estetik özelliklerinin diğer yapıştırma simanlarına göre daha iyi olması rezin simanların kullanımını artırmaktadır.

Laboratuvarda gerçekleştirilen in vitro bağlanma testlerinde çekilmiş insan dişleri rutin olarak kullanılmaktadır. Örneklerin hazırlanmasında standardizasyonun sağlanması ve makaslama bağlanma dayanıkılığı için hazırlanacak örneklerde yeterli genişlikte bağlanma yüzeylerinin elde edilmesi amaçları ile çalışmamızda periodontal ve protetik nedenlerle çekilmiş, çürüksüz ve kron kısmında herhangi bir defekt, restorasyon ya da çatlak içermeyen üst çene anterior kesici dişler kullanıldı. Çürük gibi bir uyaran varlığında tamir dentini oluşumu sonucunda bağlantı dayanıkılığının tespitinde standardizasyon sağlanamaması sonuçları olumsuz etkileyecektir ${ }^{14-17}$.

Seçilen dişlerin standardize edilmesi tek başına yeterli değildir. Bu dişlerin saklama koşulları da belirli kurallara uymalıdır. Bağlantı dayanıklılık testi uygulanacak dişlerin çekim işleminden sonra kullanılacağı ana kadar geçen sürede dehidrate olmasını önlemek amacıyla, solüsyonlar içinde tutulması gerekmektedir ${ }^{18-}$ 20. Distile su ve salin bu amaçla kullanılan solüsyonlardır. Mevcut çalışmada çekilmiş dişler oda sıcaklığında distile su içerisinde muhafaza edilmiştir.

Mikroorganizmaların üremesini engellemek amaciyla etanol, formol, timol, sodyum hipoklorit, glutaraldehit gibi antimikrobiyal maddeler saklama solüsyonuna ilave edilebilmektedir. Ancak ortamdaki kimyasal maddelerin, diş dokularını ve kullanılan materyalin özelliklerini değiştirebileceği ve bu saklama ortamlarının dental materyallerin bağlanma dayanımı üzerinde olumsuz yönde etkili olabileceği belirtilmektedir. Retief ve ark.'ları kloroamin, etanol, salin, formol ve timol gibi beş farklı solüsyon içinde saklanan dişlere uygula-

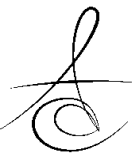


nan dolgu maddelerinin makaslama kuvvetlerine karşı bağlanma dayanımlarını incelemişler ve timol ve etanol gruplarındaki dişlerin bağlanma dayanımının diğerlerinden daha düşük olduğunu bulmuşlardır. Kompozit rezinin mineye bağlanma dayanımına farklı saklama solüsyonlarının etkisi üzerine yapılan diğer bir çalışmada, \%0.1'lik timol, \%10'luk formol ve distile su içinde bekletilen dişlerin bağlanma dayanımları incelenmiş ve en düşük bağlanma dayanımı timol solüsyonunda bekletilen dişlerden elde edilmiştir, diğer iki solüsyonda bekletilen dişler arasında bağlanma dayanımı açısından anlamlı bir fark bulunamamıştır ${ }^{21,23}$. Mevcut çalışmada çekilmiş dişlerin saklandığı ortama distile suyun dışında herhangi bir kimyasal madde ilave edilmemiştir.

Mevcut çalışmada fiber post ve döküm post kor grupları arasında istatistiki olarak anlamlı fark görülmemiştir. Fiber post uygulama kolaylığı açısından avantajıdır. Ayrıca fiber postların elastik modulusunun diş dokusuna metal alaşımlardan daha yakın olması kole bölgesinde stres yoğunlaşmasını engelleyerek hasarlı dişte kırılma olasılığını azaltacaktır. Literatürde farklı post-kor sistemlerinin kırılma dayanımlarının incelendiği çalışmalar mevcuttur. Khaledi et al. ${ }^{24} \mathrm{Ni}-\mathrm{Cr}$ ve altın alaşımının kullanıldığı post-kor sistemlerinin kırılma dayanımlarını karşılaştırmıştır. Çalışmada $\mathrm{Ni}-\mathrm{Cr}$ post kor sistemlerinin daha yüksek kırılma direnci gösterdiğini belirtmiştir. Costa et al. $^{25}$ prefabrike fiber post ve kasto- mize fiber postların kırıma kuvvetlerini karşılaştırdığı çalışmada test grupları arasında fark bulamamıştır. Oyar ${ }^{26}$, çalışmasında $\mathrm{Ni}-\mathrm{Cr}$ döküm postlarının rezin si- manlar ile birlikte kullanılmasını önererek bu kombinas- yonun kırılma dayanımını artırabileceğini belirtmiştir.

Mevcut çalışmada test sırasında meydana gelen başarısızıık tipleri değerlendirilmemiştir. Başarısızlığın nasıl gerçekleştiği önemlidir. Dişin veya postun kırıldığı durumlarda dişin çekilmesi gerekebilir. Dental implantların çok başarılı ve yaygın olarak kullanıldığı günümüz diş hekimliğinde başarısız olmuş post kor tedavisinin tekrar post kor ile tedavi edilmesi çok nadirdir. Bu nedenle test sırasında meydana gelen başarısızlık tipleri inmal edilmiştir.

Post kor sistemleri gelen çiğneme kuvvetlerine kırılmadan, deforme olmadan karşı koyabilmelidir. Çaışmamızda test edilen Li-disilikat post sistemi kırılgan camsı yapısından dolayı kırılma direnci döküm ve fiber post sistemlerinden anlamlı olarak düşük bulunmuştur.
Estetik avantajlarının fazla olmasına rağmen kırılgan yapısı bu malzemenin post-kor restorasyonlarda kullanımını olumsuz etkileyecektir.

\section{SONUÇ}

Li-disilikat diğer cam yapılı sistemlere göre çalışma tekniğinin kolaylığı ve translüsensliği ile avantaj sağlamaktadır. Ancak mevcut mekanik özellikleri ile göreceli hafif yüklere maruz kalacak restorasyonlarda tercih edilmesi doğru olacaktır.

\section{KAYNAKLAR}

1. Dilmener FT, Sipahi C, Dalkiz M. Resistance of three new esthetic post-and-core systems to compressive loading J Prosthet Dent. 2006; 95:130-6.

2. Hayashi M, Takahashi $\mathrm{Y}$, Imazato $\mathrm{S}$, Ebisu $\mathrm{S}$. Fracture resistance of pulpless

teeth restored with post-cores and crowns. Dent Mater. 2006;22:477-85.

3. Zhang $Y X$, Zhang $W H$, Lu ZY, Wang KL. Fracture strength of custom-fabricated Celay all-ceramic post and core restoredendodontically treated teeth. Chin Med J (Engl). 2006;119:181520.

4. Hayashi M, Sugeta A, Takahashi Y, Imazato S, Ebisu $S$. Static and fatigue fracture resistances of pulpless teeth restored with post-cores. Dent Mater. 2008;24:1178-86.

5. Yoldas O, Akova T,Uysal H. An Experimental analysis of stressesin simulated flared root canals subjected to various post-core applications. J Oral Rehabil. 2005;32(6):427-32.

6. Makade CS, Meshram GK, Warhadpande M, Patil PG.A comparative evaluation of fracture resistance of endodontically treated teeth restored with different post core systems -an in-vitro study. J Adv Prosthodont. 2011;3:90-5.

7. Goracci C, Ferrari M. Current perspectives on post systems: a literature review. Aust Dent J. 2011;56: 1:77-83.

8. Salameh Z, Sorrentino R, Ounsi HF, Goracci C, Tashkandi E, Tay FR, Ferrari M. Effect of different allceramic crown system on fracture resistance and failurepattern of endodontically treated maxillary $p$ remolars restored with and withoutglass fiber posts. J Endod. 2007;33:848-51. 
9. Goracci C, Grandini S, Bossù M, Bertelli E, Ferrari $M$. Laboratory assessment of the retentive potential of adhesive posts: a review. J Dent. 2007;35:82735.

10. Robbins JW. Restoration of the endodontically treated tooth. Dent Clin North Am 2002;46:367-84

11. Makade CS, Meshram GK, Warhadpande M, Patil PG. A comperative evaluation of fracture resistance of endodontically treated teeth restored with different post core systems-an invitro study J Adv Prosthodont. 2011;3:90-5.

12. Saupe WA, Gluskin HA, Radke RA. A comparative study of fracture resistance between conventional dowel and cores and a resin reinforced dowel system in the intraradicular restoration of structurally compromised roots. Quintessence Int 1996:27;483-91.

13. Pontius $\mathrm{O}$, Hutter JW. Survival rate and fracture strength of incisors restored with different post and core systems and endodontically treated teeth incisors without coronoradicular reinforcement. ] Endodon 2002;28:710-5.

14. The glossary of prosthodontic terms. J Prosthet Dent. 2005;94:10-92.

15. Pollington S. Novel Glass-ceramics for dental restorations.J Contemp Dent Pract. 2011;12:60-7.

16. Neiva G, Yaman P, Dennison JB, Razzoog ME, Lang $B R$. Resistance of fracture of three all ceramic systems. J Esthet Dent. 1998;10:60-6

17. Kato $\mathrm{H}$, Matsumura $\mathrm{H}$, Tanaka T, Atsuta M. Bond strength and durability of porcelain bonding systems. J Prosthet Dent. 1996;75:163-8

18. Dilmener FT, Sipahi C, Dalkiz M. Resistance of three new esthetic post-and-core systems to compressive loading. J Prosthet Dent. 2006;95: 130-6.

19. Goracci C, Ferrari M. Current perspectives on post systems: a literature review. Aust Dent J. 2011; 56:77-83.

20. Rasimick BJ, Wan J, Musikant BL, Deutsch AS. A review of failure modes in teeth restored with adhesively luted endodontic dowels. ] Prosthodont. 2010;19:639-46

21. Belli S, Eraslan O, Eskitascioglu G, Karbhari V. Monoblocks in root canals:a finite elemental stress analysis study. Int Endod J. 2011;44(9):817-26.

22. Köroğlu A, Ekren O, Kurtoglu C. Geleneksel ve adeziv dental simanlar hakkında bir derleme çalışması. Atatürk Üniv Diş Hek Fak 2012:205-16.

23. Retief DH, Wendt SL, Bradley EL, Denys FR. (1989). The effect of storage media and duration of storage of extracted teeth on the shear bond strength of Scotchbond 2/Silux to dentin. Am J Dent, 1989;2:269-73.

24. Khaledi AA, Sheykhian S, Khodaei A. Evaluation of Retention of two Different Cast Post-Core Systems and Fracture Resistance of the Restored Teeth. J.Dent(Shiraz) 2015; 16:121-128

25. Costa RG, De Morais EC, Campos EA, Michel MD, Gonzaga CC, Correr GM. Customized fiber glass posts. Fatigue and fracture resistance. Am J Dent. 2012;25:35-8.

26. Oyar P.The effects of post-core and crown material and luting agents on stress distribution in tooth restorations. J Prosthet Dent. 2014;112:211-9
Yazışma Adresi
Yrd.Doç.Dr.Orhun EKREN
Çukurova Üniversitesi Diş Hekimliği
Fakültesi Protetik Diş Ted. A.D Balcalı
Sarıçam/Adana
Tel: 0(533)7175954
e-mail:oekren@cu.edu.tr 